\title{
Could Serum Testosteron Level and Body Mass Index Predict Psa Relaps in Prostate Cancer Patients undergoing Radical Surgery?
}

\author{
Adnan Sımsır, Cag Cal*, Rashad Mammadov, Ibrahim Cureklıbatır and Gurhan Gunaydın
}

Ege University School of Medicine, Department of Urology, Izmir, Turkey

\begin{abstract}
Purpose: It is well-known that indicators such as biopsy and prostatectomy Gleason score, clinical and pathological stage and preoperative PSA level can be utilized in predicting PSA recurrence in cases who underwent radical prostatectomy (RP) with the diagnosis of organ-confined prostate cancer. The purpose of this study was to investigate the predictability of postoperative PSA recurrence by serum total testosterone levels as well as body mass index (BMI).

Materials and methods: Fourty-eight patients in whom RP was planned with the diagnosis of prostate-confined cancer were enrolled in this study. The data recorded included the patient's preoperative testosterone levels and $\mathrm{BMI}$ as well as age, serum PSA level, clinical stage, Gleason score on biopsy, the presence of PIN and surgical margin positivity. After operation, the patients were kept under follow up according to the guidelines. During the follow-up, the analysis of the selected markers was performed using T-test, Mann-Whitney U test, Chi square test, Anova and Roc analysis in cases with documented PSA recurrence.
\end{abstract}

Results: Serum total testosterone level, BMI, surgical margin positivity and Gleason score and preoperative PSA level are independent variables that affect PSA recurrence. On Roc analysis, a testosterone level of less than $2,81 \mathrm{ng} / \mathrm{dL}$ was found to be significant for the prediction of PSA recurrence $(p=0.04)$.

Conclusion: From this study, we concluded that, besides proven risk factors for PSA recurrence (Pre op. PSA level, Gleason score, surgical margin positivity and stage), preoperative low testosterone levels and high BMI can also be predictive.

Keywords: Prostate; Adenocarcinoma; Testosterone; Body Mass Index; Prostate-specific antigen

\section{Introduction}

Radical prostatectomy (RP) remains the gold standard for the treatment of localized prostate cancer in patients with a life expectancy of more than 10 years $[1,2]$. It is well-known that indicators such as biopsy and prostatectomy Gleason score, pathological stage, preoperative PSA level and surgical margin positivity (SMP) can be utilized in predicting PSA recurrence in cases who underwent radical prostatectomy with the diagnosis of organ-confined prostate cancer $[3,4]$. Given that prostate adenocarcinoma is a testosterone-dependent tumor, there is a limited number of studies investigating how PSA recurrence is influenced by testosterone levels and obesity that affects hormone levels.

In this study, we investigated the role that body mass index (BMI) as well as preoperative serum total testosterone levels play in the course of the disease in patients who underwent RP with the diagnosis of clinically localized prostate cancer and were followed up.

\section{Materials and Methods}

Fourty eight patients who underwent RP with the diagnosis of prostate confined cancer in single center between 2005 and 2006 were enrolled in this study. The data recorded included the patient's preoperative total testosterone levels and BMI as well as age, serum free and total PSA levels, Gleason score on biopsy, the presence of perineural invasion (PNI), post RP prostate volume and SMP. A positive surgical margin is defined as the presence of tumor at the inked surface of the resected specimen. A positive surgical margin can be resulted from an insicion of a tumor with extraprostatic extension or iatrogenic incision of an organ-confined cancer $[5,6]$.
Testosterone levels were taken as the mean value of two measurements performed before operation and chemiluminescence was used as the method of choice. All operations were performed in a retropubic manner as described by Walsh [7]. After operation, the patients were followed up initially at month 3 , then at six months intervals in the second year and subsequently on a yearly basis. Patient follow up was performed using measurements of serum PSA levels and digital rectal examination. The diagnosis of biochemical recurrence was established in patients with a PSA level of $0.2 \mathrm{ng} / \mathrm{dl}$ or greater in two subsequent measurements. Time to recurrence was recorded in months. The above mentioned parameters that are likely to influence recurrence were investigated in patients with PSA recurrence.

Data analysis was performed using SPSS statistical software version 15. The T-test, Mann-Whitney U test, Chi square test, Anova and Roc analysis were the methods of choice.

\section{Results}

The 48 patients included in this study had a mean age of 62.6 (51-

*Corresponding author: Adnan Sımsır, EÜTF Hastanesi 4. kat Üroloji AD,Bornova İmir, Turkey, Tel: +90 23239025 17; Fax:+90 533 3364354; E-mail: adnan.simsir@ege.edu.tr

Received October 06, 2011; Accepted November 17, 2011; Published Novembe 19, 2011

Citation: Sımsır A, Cal C, Mammadov R, Cureklıbatır I, Gunaydın G (2011) Could Serum Testosteron Level and Body Mass Index Predict Psa Relaps in Prostate Cancer Patients undergoing Radical Surgery? J Cancer Sci Ther S1. doi:10.4172/1948-5956.S1-007

Copyright: (C) 2011 Sımsır A, et al. This is an open-access article distributed under the terms of the Creative Commons Attribution License, which permits unrestricted use, distribution, and reproduction in any medium, provided the original author and source are credited. 
73), a mean PSA level of 8.2 (2.1-19.3), a mean BMI of 26.4 (20.2-33.2) and a mean testosterone level of $4.1 \mathrm{nmol} / \mathrm{ml}(2.02-6.1)$. None of the patients received adjuvant therapy in the postoperative early period. Table 1 summarizes the characteristics of the patients.

The mean follow up time of patients was 56.6 (48-70) months. All patients were kept under follow-up and none of the patients were excluded from the study. Biochemical recurrence was detected in a total of 12 patients (25\%) who had a mean PSA level of $0.7(0.2$ 1.3). Recurrence occurred on postoperative month 17 in average. The analyses performed revealed that serum total testosterone levels $(\mathrm{p}<0.001)$, BMI $(\mathrm{p}=0.04)$, SMP $(\mathrm{p}<0.001)$, biopsy and RP sample Gleason score $(\mathrm{p}=0.036$ and $\mathrm{p}<0.001)$, pathological $\mathrm{T}$ stage $(\mathrm{p}<0.001)$ and preoperative PSA levels $(\mathrm{p}=0.02)$ were the independent variables affecting PSA recurrence (Table 2).

Seven of 10 patients with positive surgical margin had biochemical recurrence whereas 3 patients have not had PSA progression. Regarding the parameters that are likely to affect SMP, there were no findings other than gleason scores $(\mathrm{p}<0.001)$. However, when these parameters were investigated based on BMI classification, positive surgical margins were observed in 5 of 8 patients $\left(30-39.9 \mathrm{~kg} / \mathrm{m}^{2}\right)$ diagnosed as obese $(\mathrm{p}<0.001)$. No significant findings were noted in terms of the relationship between total testosterone levels and BMI $(\mathrm{p}=0.09)$ whereas there was a significant inverse proportion between patients with extraprostatic extension and testosterone levels $(\mathrm{p}=0.05)$.

Roc analysis of total testosterone level detected as an independent predictor by multivariate analysis revealed that a testosterone level of less than $2.81 \mathrm{ng} / \mathrm{ml}$ was significant for the prediction of PSA recurrence $(\mathrm{p}=0.047)$.

\begin{tabular}{|l|l|}
\hline Patient Characteristics & No.of patients \\
\hline Total patients & 48 \\
\hline Median age & $62.6(51-73)$ \\
\hline PSA level & $8.2(2.1-19.3)$ \\
\hline Biopsy Gleason score & $6.2(6-7)$ \\
\hline Prostatectomy Gleason score & $6.4(6-8)$ \\
\hline Biopsy PNI & $14 \quad(\% 29.1)$ \\
\hline Prostate volume(cc) & $41.4(28-76)$ \\
\hline BMI & $26.4(20.2-33.2)$ \\
\hline Serum testosterone level Stage (p) & $4.1(2.02-6.1)$ \\
\hline pT2 & $37(\% 77.1)$ \\
\hline pT3 & $11 \quad(\% 32.9)$ \\
\hline PSM & $10(\% 20.8)$ \\
\hline Biochemical failure & $12 \quad(\% 25)$ \\
\hline
\end{tabular}

PNI: Perineural invasion, PSM: Positive surgery margin

Table 1: Patient Characteristics.

\begin{tabular}{|l|l|l|l|}
\hline Parameters & Value(no) & PSA relapse(\%) & P \\
\hline PSA & 8.2 & $12(25.0)$ & 0.02 \\
\hline Biopsy PNI & 14 & $4(28.5)$ & 0.11 \\
\hline Prostatectomy gleason sum & 6.4 & $12(25.0)$ & $<0.001$ \\
\hline Prostate volume & 41.4 & $12(25.0)$ & 0.24 \\
\hline PSM & 10 & $7(70.0)$ & $<0.001$ \\
\hline ECE & 8 & $2(25.0)$ & 0.07 \\
\hline BMI & 26.4 & $12(25.0)$ & 0.04 \\
\hline Testosterone level & 4.1 & $12(25.0)$ & $<0.001$ \\
\hline
\end{tabular}

ECE: Extracapsular extansion

Table 2. The relationship between the investigated parameters and PSA recurrence.

\begin{tabular}{|l|l|l|l|l|}
\hline Parameters & Normal (18.5-24.9) & $\begin{array}{l}\text { Over weight } \\
(25.0-29.9)\end{array}$ & $\begin{array}{l}\text { Obese } \\
(30.0-39.9)\end{array}$ & $P$ \\
\hline No.of patients & 13 & 27 & 8 & \\
\hline Pre RP PSA & 6.4 & 10.3 & 14.03 & $<0.001$ \\
\hline Serum testosterone & 5.9 & 5.8 & 4.9 & 0.091 \\
\hline Gleason score & 7.02 & 6.91 & 7.64 & 0.19 \\
\hline ECE & $1(\% 7.7)$ & $1(\% 3.7)$ & 0 & 0.64 \\
\hline PSM & $2(\% 15.4)$ & $3(\% 11.1)$ & $5(\% 62.5)$ & $<0.001$ \\
\hline PSA relapse & $1(\% 7.7)$ & $7(\% 25.9)$ & $4(\% 50)$ & $<0.001$ \\
\hline
\end{tabular}

Table 3: The relationship between the investigated parameters and BMI grouping.

Finally, the operated patients were classified according to BMI international classification and the presence of a relationship with the investigated parameters was investigated. Accordingly, as BMI increased there was a significant relationship between PSA recurrence and preoperative PSA levels and surgical margin positivity (Table 3).

\section{Discussion}

In this study, we found that preoperative testosterone levels of less than $2.8 \mathrm{ng} / \mathrm{dl}$ was an important risk factor for biochemical disease recurrence in patients undergoing RP. A review of literature also revealed an inversely proportional relationship between testosterone levels and the aggressivity of the disease, in parallel with this finding [8-11]. Sufficient data to elucidate the mechanism of this relationship can not be obtained from the literature. However, it is a known fact that low testosterone levels indicate that the disease will follow an aggressive course. The most satisfactory explanation in the literaure is that decreased testosterone level is not a cause but a result of the aggressivity of the disease. Miller et al. [12] advocate that inhibin-alpha produced intensely by PC cells affect hypothalamo-pituitary axis, thus reducing testosterone levels. Similarly, Risbridger et al. [13] examined 174 patients and obtained the same result. The rapid increase in post RP testosterone levels and the decrease in inhibin-alpha was one of the reasons why the author advocated the hypothesis related to inhibinalpha. However, studies by Marks et al. [14] and Freedland et al. [15] demonstrated no relationship between testosterone levels and the course of the disease.

One of the results of this study is the positive relationhip between obesity and PSA recurrence. The positive relationship between obesity and the likelihood of developing prostate cancer has been confirmed by a number of studies carried out with large sample size [16,17]. However, the relationship between obesity and post RP recurrence has not been completely elucidated. Even though obesity was identified as a risk factor for PSA recurrence in a study of 3162 patients by Amling et al. [18] the fact that most patients with recurrence were AfricanAmerican led to questioning of the reliability of the results of the mentioned study. A study by Freedland et al. [19] reported obesity as a risk factor for PSA recurrence. Freedland [19] suggested that increased aromatase activity in adipose tissue may lead to more aggressive tumor development due to increased testosterone-to-estrogen conversion and decreased testosterone levels. Additionally, mitogenic agents that increase with obesity such as serum leptin, insulin, insulin-like growth factor 1 affect the course of the disease.

In addition, SMP in patients with a BMI of 30 or over is also noteworthy. It is well known that surgery is much more difficult and less comfortable with obese patients than that with other patients. Under these circumstances, we believe that high SMP rate is one of the causes of early PSA recurrence in obese patients. 


\section{Conclusion}

In this study, we concluded that, besides proven risk factors for PSA recurrence (preop, PSA level, gleason score, SMP and stage), preoperative low testosterone levels and high BMI can also be predictive in patients undergoing RP. However, further well-designed, multi-center studies including patients from different ethnic groups are warranted for these two parameters mentioned to be included in nomograms.

\section{References}

1. Amling CL, Blute ML, Bergstralh EJ, Seay TM, Slezak J, et al. (2000) Longterm hazard of progression after radical prostatectomy for clinically localized prostate cancer: continued risk of biochemical failure after 5 years. J Urol 164 : 101-105.

2. Pound CR, Partin AW, Eisenberger MA, Chan DW, Pearson JD, et al (1999) Natural history of progression after PSA elevation following radical prostatectomy. JAMA 281: 1591-1597.

3. Kattan MW, Wheeler TM, Scardino PT (1999) Postoperative nomogram for disease recurrence after radical prostatectomy for prostate cancer. J Clin Oncol 17: $1499-1507$.

4. Hull GW, Rabbani F, Abbas F, Wheeler TM, Kattan MW, et al. (2002) Cancer control with radical prostatectomy alon 1000 consecutive patients. J Urol 167: 528-534.

5. Ohori M, Wheeler TM, Kattan MW, Goto Y, Scardino PT (1995) Prognostic significance of positive surgical margins in radical prostatectomy specimens. J Urol 154: 1818-1824

6. Wieder JA, Soloway MS (1998) Incidence, etiology, location, prevention and treatment of positive surgical margins after radical prostatectomy for prostate cancer. J Urol 160: 299-315.

7. Walsh PC (1998) Anatomic Radical prostatectomy : Evolution of the surgical technique. J Urol 160: 2418-2424.

8. Isom-Batz G, Bianco FJ Jr, Kattan MW, Mulhall JP, Lilja H, et al. (2005) Testosterone as a predictor of pathalogical stage in clinically localized prostate cancer. J Urol 173: 1935-1937.
9. Partin AW, Pound CR, Clemens JQ, Epstein JI, Walsh PC (1993) Serum PSA after anatomic radical retropubic prostatectomy. The Johns Hopkins experience after 10 years. Urol Clin North Am 20: 713-725.

10. Han M, Partin AW, Pound CR, Epstein JI, Walsh PC (2001) Long term biochemical disease free and cancer spesific survival following anatomic radical retropubic prostatectomy. The 15 year Johns Hopkins experience. Urol Clin North Am 28: 555-565.

11. Teloken C, Da Ros CT, Caraver F, Weber FA, Cavalheiro AP, et al. (2005) Low testosterone levels are associated with positive surgical margins in radical retropubic prostatectomy: hypogonadism represents bad prognosis in prostate cancer. J Urol 174: 2178-2180.

12. Miller LR, Partin AW, Chan DW, Bruzek DJ, Dobs AS, et al. (1998) Influence of radical prostatectomy on serum hormone levels. J Urol 160: 449-453.

13. Risbridger GP, Shibata A, Ferguson KL, Stamey TA, McNeal JE, et al. (2004) Elevated expression of inhibin alfa in prostate cancer. J Urol 171: 192-196.

14. Marks LS, Mazer NA, Mostaghel E, Hess DL, Dorey FJ, et al. (2006) Effects of testosteron replacement therapy on prostate tissue in men with late-onse hypogonadism. JAMA 296: 2351-2361.

15. Freedland SJ, Isaacs WB, Platz EA, Terris MK, Aronson WJ, et al. (2005) Prostate size and risk of high grade advanced prostate cancer and biochemical progression after radical prostatectomy: a search database study. J Clin Onco 23: $7546-7554$

16. Andersson SO, Wolk A, Bergström R, Adami HO, Engholm G, et al. (2005) Body size and prostate cancer : a 20 year follow-up study among 135,006 Swedish construction workers. J Natl Cancer Inst 89: 385-389.

17. Kane CJ, Bassett WW, Sadetsky N, Silva S, Wallace K, et al. (2005) Obesity and prostate cancer: clinical risk factors at presentation: data from CaPSURE. J Urol 173: 732-736.

18. Amling CL, Riffenburgh RH, Sun L, Moul JW, Lance RS, et al. (2004) Pathologic variables and recurrence rates as related to obesity and race in men with prostate cancer undergoing radical prostatectomy. J Clin Oncol 22: 439-445.

19. Freedland SJ, Aronson WJ, Kane CJ, Presti JC Jr, Amling CL, et al. (2004) Impact of obesity on biochemical control after radical prostatectomyclinically localized prostate cancer: a report by the Shared Equal Acces Regional Cancer Hospital database study group. J Clin Oncol 22: 446-453.
This article was originally published in a special issue, Prostate Cancer handled by Editor(s). Dr. Gary Guishan Xiao, Creighton University, USA; Dr. Sreenivasa R. Chinni, Wayne State University, USA 